\title{
Status and community-based conservation of marine turtles in the northern Querimbas Islands (Mozambique)
}

\author{
Julie Garnier, Nicholas Hill, Almeida Guissamulo, Isabel Silva \\ MATTHEW WitT and BRENDAN GODLEY
}

\begin{abstract}
Situated in the northernmost part of Mozambique, the northern Querimbas Islands support some of the most diverse and pristine coral reefs in the Western Indian Ocean. The community-based turtle conservation programme that we developed on Vamizi Island has facilitated the identification and protection of a key nesting site for the green marine turtle Chelonia mydas in Mozambique, with a mean of 122 nests per year. The area is also used by nesting female and immature hawksbill turtles Eretmochelys imbricata. Nesting activity of green turtles was observed all year round, with a peak in the summer (February-March). Incubation periods of this species showed seasonal fluctuations inversely correlated with air temperature. Hatching success was high $(87 \%)$ when nests were not lost through tidal overwash and erosion, which affected nearly $40 \%$ of all nests in 2007 . Using satellite tracking of four green turtles nesting on Vamizi we identified foraging grounds in marine protected areas in Kenya, Tanzania and north-west Madagascar. Migratory routes of two individuals along the East African coast were generally neritic and all passed through the waters of multiple nations and as many as six marine conservation areas, emphasizing the importance of regional cooperation. Awareness programmes were also conducted with resource users, and the development of a community-based management system triggered the creation of a marine sanctuary by the local community.
\end{abstract}

Keywords Community-based conservation, green turtle, hawksbill turtle, migratory routes, Mozambique, population dynamics, satellite tracking

\section{Introduction}

Conservation of marine resources is a challenge because of the ever-increasing pressure on marine biodiversity and the gaps in our knowledge of the biology of important

JUlie GARNIER (Corresponding author) and Nicholas Hill The Zoological Society of London, Regent's Park, London, NW1 4RY, UK. E-mail juliegarnier@ hotmail.com

Almeida Guissamulo Natural History Museum, Maputo, Mozambique

ISABEL SILVA Unilúrio University, Cabo Delgado, Mozambique

Matthew WitT and Brendan Godley Marine Turtle Research Group, Centre for Ecology and Conservation, School of Biosciences, University of Exeter, UK

Received 11 February 2011. Revision requested 28 July 2011.

Accepted 20 September 2011. species such as marine turtles, which are migratory (Hawkes et al., 2009). Marine turtles in the Western Indian Ocean are categorized globally as Vulnerable (olive ridley Lepidochelys olivacea), Endangered (green Chelonia mydas, loggerhead Caretta caretta) and Critically Endangered (hawksbill Eretmochelys imbricata) on the IUCN Red List (IUCN, 2011).

In this region the green turtle has the widest distribution, with nesting sites scattered over many small islands and along the coasts of East Africa and Madagascar (Frazier, 1975). Centuries of overexploitation and habitat destruction have led to some populations being depleted but, following the implementation of long-term conservation programmes, the status of some populations has improved and numbers of nesting females have increased (e.g. Bourjea et al., 2007a). The largest rookeries have now been reported in the Comoros archipelago, with $>2$,00o green turtle females on Mayotte and 1,000-3,000 on Moheli (Bourjea et al., 2007a), in the Seychelles archipelago (Farquhar and Aldabra groups) with 3,500-4,700 females (Mortimer, 1985), and in Iles Eparses (Europa and Tromelin Islands) with 2,000-11,00o females (Le Gall et al., 1986). Other sites along the coasts of Madagascar, Tanzania and Kenya host much smaller green turtle rookeries (Okemwa et al., 2004; Muir, 2005; Bourjea et al., 2006).

Populations of hawksbill turtles have declined extensively because of the international trade in turtle shell and the largest nesting sites for this species in the Western Indian Ocean are in the Seychelles, where population increases have been recorded on the two islands that have been well protected since the 1970s (Mortimer, 2006; Mortimer \& Donnelly, 2008; Allen et al., 2010). Large nesting populations also occur in Madagascar but are still declining because of continued exploitation for turtle products (Mortimer \& Donnelly, 2008).

In South Africa conservation and monitoring programmes for the leatherback Dermochelys coriacea and loggerhead turtles have continued for $>4$ decades (Hughes, 1996). In Mozambique five species of marine turtles are known to nest (Hughes, 1971) but knowledge of their status and biology is poor because the country was ravaged by nearly 3 decades of war (Louro et al., 2006; Videira et al., 2008). The first conservation initiatives only started in the 1990s, in southern Mozambique, which provides important nesting grounds for loggerhead and leatherback turtles (Gove \& Magane, 1996; Louro et al., 2006). In 200813 turtle 


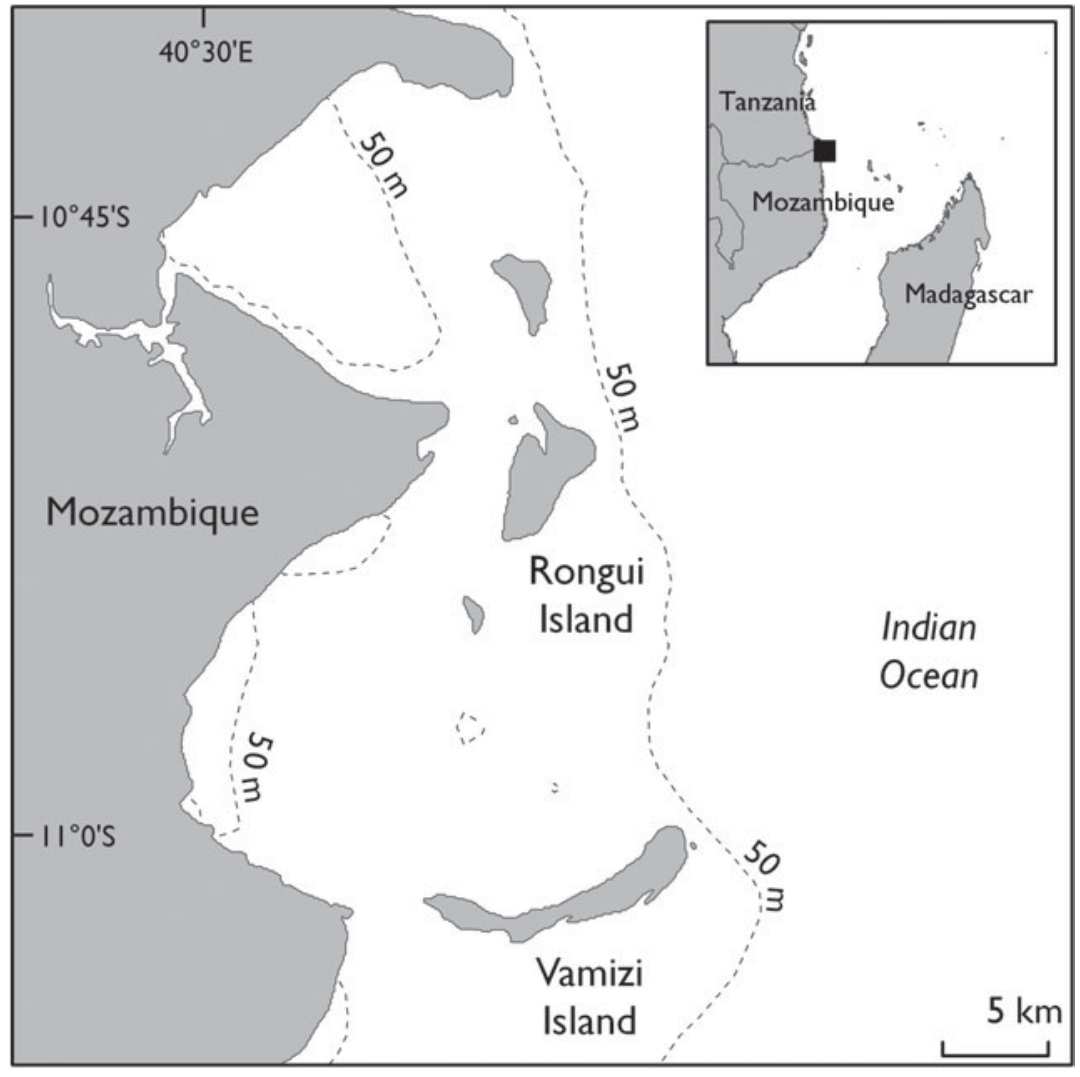

FIG. 1 The location of Vamizi Island in the Querimbas archipelago off the coast of Mozambique. The inset shows the location of the main map. conservation programmes were reported, focusing on conservation awareness and nest protection but only covering 9\% of Mozambique's coastline (Videira et al., 2008). In the north green and hawksbill turtles are the predominant species and have been observed to nest in the Querimbas National Park as well as on Primeiras and Segundas Islands (Hughes, 1971; Costa et al., 2007; Videira et al., 2008).

Here we report the results of a community-based turtle conservation programme that was initiated in northern Querimbas, on Vamizi Island. The programme, the Maluane Project, was developed as a partnership between the Zoological Society of London, local communities, the Mozambican government and the private sector. The programme seeks ecological sustainability through scientifically-based management, socio-economic sustainability through the strong involvement of local communities at all levels, and financial sustainability by the development of upmarket tourism (Garnier, 2003). The fundamental goal of our study was to acquire knowledge about the nesting and migration patterns of marine turtles nesting on Vamizi Island. The ultimate goal is to develop a sustainable, local turtle conservation programme and to contribute to the development of turtle conservation strategies regionally.

\section{Study area}

Vamizi Island is one of the northernmost islands of the Querimbas archipelago, a continuous chain of 32 islands and several reef complexes that stretches for c. $200 \mathrm{~km}$ along the coast of the Cabo Delgado Province in northern Mozambique (Fig. 1). The Northern Querimbas islands support some of the healthiest coral reefs in the Western Indian Ocean and probably play a key role in the region as they lie in the area where the south Equatorial Current splits into the south-flowing Mozambican Current and northflowing East African Coastal Current (Lutjeharms et al., 2000; Schouten et al., 2003; Hill et al., 2009). The climate is strongly influenced by the southern end of the East African Monsoon System and most rain falls between December and April, with south-easterly winds predominating in March-September and northerly winds in OctoberFebruary.

The 1,181-ha Vamizi is one of the largest islands in the archipelago and is bounded to the east by bathymetric intrusions that provide proximity to the deep water of the Mozambique Channel. Its resident community, whose subsistence is based on fishing, has doubled in recent years through immigration of itinerant fishers from Tanzania and other provinces in Mozambique (Garnier, 2003; Garnier et al., 2008). There are three local settlements in the west and a small tourism lodge in the north-east. The main turtle nesting beaches (Comisete, Farol) are in the east, covering a total of $6.5 \mathrm{~km}$ of coast, with a small $(<50 \mathrm{~m})$ nesting beach (Munto Nkulu) also used in the south. Interviews with fishers and direct observations made prior to the project suggested that the proportion of nesting 
TABLE 1 Months of night-time monitoring, number of adult female green turtle Chelonia mydas tagged, number of clutches laid by tagged females, observed clutch frequency and estimated mean clutch frequency \pm SD on Vamizi Island in the Querimbas archipelago off the coast of Mozambique (Fig. 1).

\begin{tabular}{lllllc}
\hline & 2004 & 2005 & 2006 & 2007 & All \\
\hline Months with night patrols & March-July & April-July & April-June & January-May & \\
No. of nesting females tagged & 11 & 12 & 18 & 14 & 55 \\
No. of clutches laid by tagged females (\%) & $39(48 \%)$ & $42(31 \%)$ & $36(22 \%)$ & $31(25 \%)$ & $149(29 \%)$ \\
Observed clutch frequency & 3.5 & 3.5 & 2.0 & 2.2 & 2.7 \\
Estimated mean clutch frequency $\pm \mathrm{SD}^{2}$ & $3.5 \pm 2.5$ & $3.1 \pm 1.7$ & $1.9 \pm 1.3$ & $1.9 \pm 1.0$ & $2.5 \pm 1.8$ \\
\hline
\end{tabular}

${ }^{1}$ Number of clutches laid by tagged females divided by the number of tagged females

${ }^{2}$ Observed clutch frequency corrected for unobserved nests (Broderick et al., 2002). See text for details.

females killed for food was high (with many turtle carapaces observed in fishers' camps) and that there is a long tradition of egg consumption.

\section{Methods}

\section{Data collection}

Data were collected by a team of 15 turtle monitors who were selected by local leaders and had good local knowledge, having mainly been engaged in fishing activities. The team was trained in relevant turtle monitoring techniques (nest identification and excavation, turtle tagging and biometric measurements) and was structured according to individual abilities. The team was supervised by a marine biologist on site.

All nesting beaches (Comisete, Farol, Munto Nkulu) were surveyed daily between October 2003 and September 2007. All adult nesting emergences and their location were recorded. Species and clutch deposition were ascertained after observation of crawls and of the size and shape of tracks (Pritchard \& Mortimer, 1999; Schroeder \& Murphy, 1999). To record hatching and emergence data (number of eggs, including predated, un-hatched and undeveloped, number of live and dead hatchlings) nests were excavated the day after hatching had been detected.

Night-time monitoring was conducted on the two main nesting beaches (Comisete, Farol) from 2004 to 2007 for 3-5 months during January-July (Table 1). Beaches were patrolled every hour and when a turtle was detected she was left to lay her clutch and then marked with two external tags (Stockbrands, Perth, Australia) on the front flippers and one Passive Internal Transponder (Animalcare, Dunnington, $\mathrm{UK}$ ) in the shoulder. Biometric measurements (CCL, minimum curved carapace length; CCW, minimum curved carapace width) were each recorded three times for each individual (Bolten, 1999).

Satellite transmitters (Kiwisats 101, Sirtrack, New Zealand) were deployed on four green turtle females nesting on Vamizi Island between 2007 and 2009; they were tracked with the Argos system. The transmitters were attached following the protocol of Godley et al. (2002b), using epoxy resin (Fast Set Formula-Power Fast, Powers, USA) once females had finished laying their clutch and were camouflaging their nest.

\section{Data analysis}

Overall nesting success was calculated as the proportion of nesting activities that resulted in a nest (Godley et al., 2001). Hatching and emergence successes were defined as the proportion of hatchlings that hatched out of their shells and the proportion of hatchlings that reached the beach surface, respectively (Miller, 1999). The mean inter-nesting interval was calculated as the mean of all observed inter-nesting intervals, after excluding intervals $<_{7}$ days, which were considered to represent aborted nesting events (Bourjea et al., 2007a).

Two methods were used to estimate clutch frequency of individuals. The observed clutch frequency was obtained by dividing the number of clutches laid by tagged females by the number of tagged females, and the estimated mean clutch frequency was calculated as the observed clutch frequency corrected for the missing nests that had not been observed (Johnson \& Ehrhart, 1996; Broderick et al., 2002). Corrections were based on the assumptions that for internesting intervals $>20$ days and $<60$ days one clutch had been missed, and for inter-nesting intervals $>60$ days two clutches had been missed.

Satellite data were downloaded and managed using the Satellite Tracking and Analysis Tool (Coyne \& Godley, 2005). Routes were reconstructed using location classes (LC $3,2,1, \mathrm{~A})$ and biologically realistic speeds $\left(<5 \mathrm{~km} \mathrm{~h}^{-1}\right.$; Luschi et al., 1998, Hays et al., 2001). Once a turtle had stopped progressing with a directed movement along the coast she was considered to have reached her final destination (Hays et al., 2002).

\section{Foraging areas}

To obtain an insight into the foraging aggregations in the region an incentive programme was developed with fishers, 

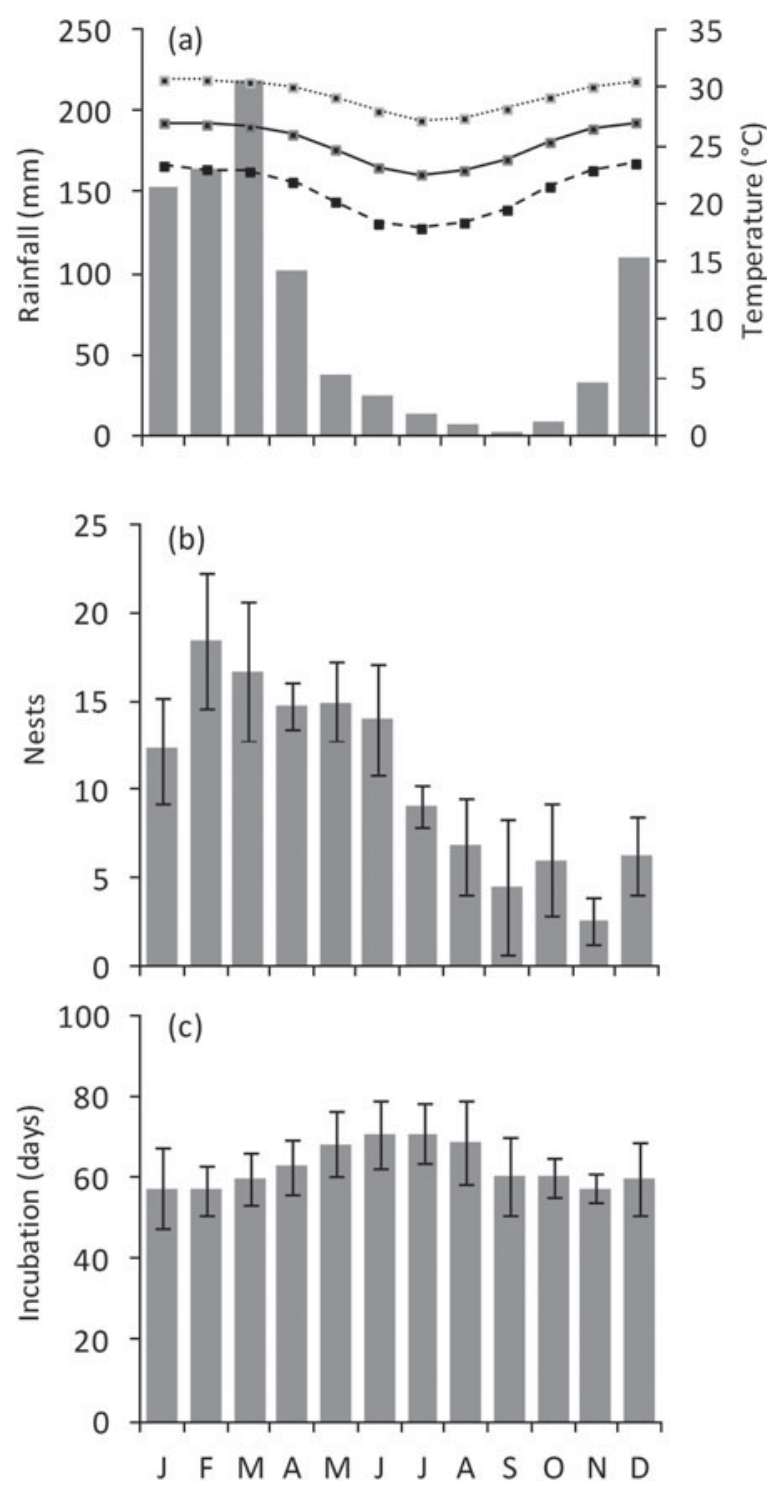

FIG. 2 (a) Monthly air temperature (maximum, mean, and minimum) and rainfall in Cabo Delgado. (b) nesting activity (mean \pm SD) and (c) monthly incubation period (mean \pm SD) of green turtles nesting on Vamizi Island (Fig. 1) between October 2003 and September 2007. Incubation periods were categorized according to the date when the nest was laid.

who were encouraged to bring live turtles caught in their nets to the project headquarters. Turtles were measured and tagged before being released, and informal interviews were conducted with the local fishers. They were subsequently given a project T-Shirt and a cash reward (c. USD 4), the value of which was intended to offset the opportunity costs of travel time to the project base.

\section{Results}

\section{Population characteristics}

A total of 639 emergences of green turtles were observed from October 2003 to September 2007 on Comisete, Farol

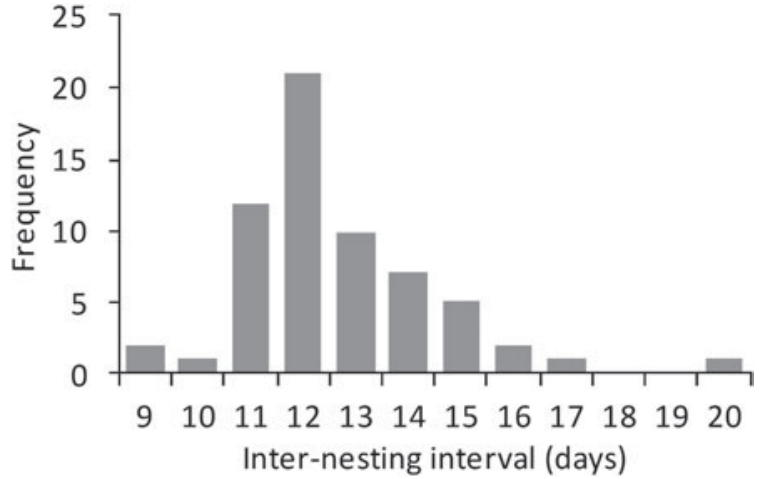

FIG. 3 Frequency of inter-nesting intervals of green turtles Chelonia mydas on Vamizi Island beween April 2004 and May 2007.

and Munto Nkulu beaches combined. The mean annual number of nests was $122 \pm$ SD 29.9 (range 78-157) and the overall nesting success was $75 \%$. Nesting activity was detected all year round (Fig. 2b) but $72.8 \%$ of nests were observed in January-June. The number of nests peaked in February. A total of nine hawksbill nests were detected on Vamizi, with a mean annual number of nests of $2.2 \pm$ SD 1.7 (range 0-4).

Between March 2004 and September 2007 a total of 55 nesting green turtles were tagged. Their CCL was $85-119 \mathrm{~cm}$ (mean 106.3 \pm SD $6.1 \mathrm{~cm}, \mathrm{n}=61$ ) and their $\mathrm{CCW} 79-140 \mathrm{~cm}$ (mean $100 \pm S D 7.5 \mathrm{~cm}, \mathrm{n}=61$ ). Mean clutch size was $112.01 \pm S D$ 23.22 (range 35-182, $\mathrm{n}=347$ ). The modal observed inter-nesting interval was 12 days (Fig. 3), with a mean interval of $12.9 \pm \mathrm{SD} 2$ days (range $9-20, \mathrm{n}=73$ ). Tagged green turtle females accounted for $29 \%(\mathrm{n}=149)$ of all nests laid during the study, which makes it difficult to ascertain the clutch frequency. If, however, we consider that each female deposits a mean of 2.5 clutches per year (Table 1), we estimate that c. 50 females breed each year.

The mean incubation period of green turtles on Vamizi was $63.1 \pm \mathrm{SD} 9.3$ days, (range 40-88, $\mathrm{n}=329$ ), with some cyclic variation throughout the year $(.2 c)$ and a significant correlation with mean air temperature $\left(r^{2}=\right.$ $-0.86, \mathrm{P}<0.005$ ). For nests that were not inundated (see below) mean hatching success was $87 \pm$ SD $19 \%(n=371)$, with the majority of nests (59\%) having a high hatching success $(>90 \%$ ) (Fig. 4). Emergence success was also high, with a mean of $82.1 \pm$ SD $22 \%(n=370)$. Predation of eggs was observed to be low, with $<1 \%$ of eggs being affected, mainly through predation by crabs (Ocypode sp.).

No loss of nests to poaching or illegal killing of females while nesting was observed on the monitored beaches after the commencement of the project. Nest loss through inundation was first detected in 2005, when it affected $1.3 \%$ of all nests. This proportion increased to $18.7 \%$ in 2006 and to $38.4 \%$ in 2007, mainly in March, April and September (Fig. 5). 


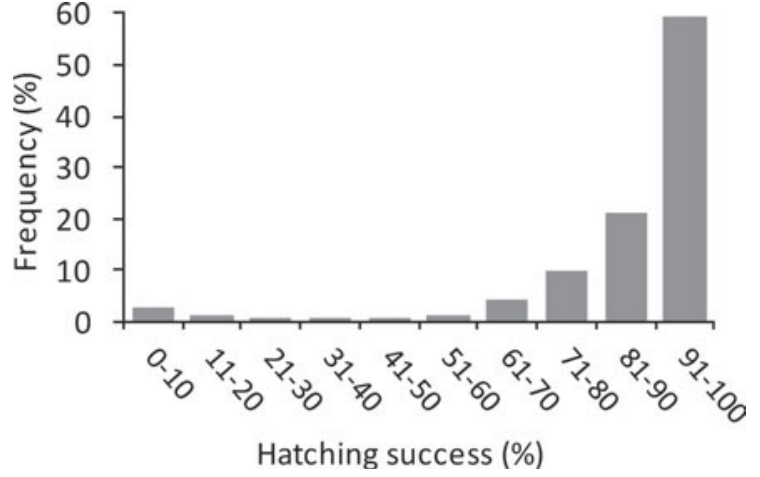

FIG. 4 Frequency of percentage hatching success of green turtle nests (those that could be excavated; $\mathrm{n}=371$ ) between March 2004 and June 2007.

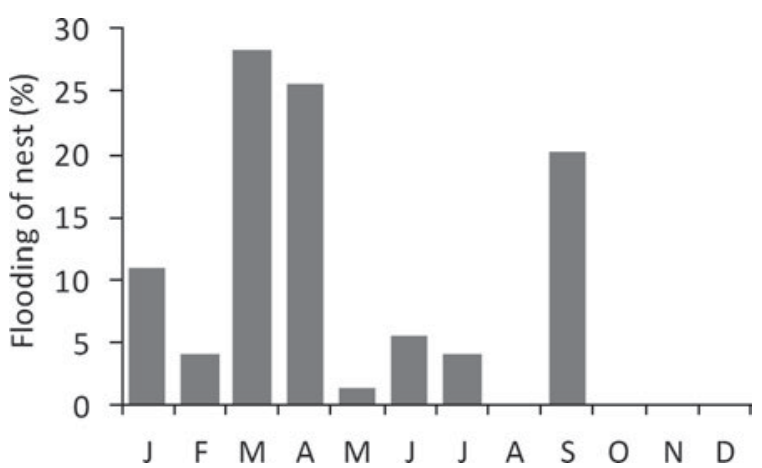

FIG. 5 Monthly percentage of green turtle nests that were flooded $(n=96)$ on Vamizi in 2006 and 2007. A nest was considered to be flooded when it had been completely overwashed.

Between October 2006 and July 2008 a total of 108 live turtles were brought to the project by fishers who operate around the island of Vamizi, of which $79.6 \%$ were hawksbill turtles. Mean CCL of these hawksbill turtles was $44 \pm$ SD $8 \mathrm{~cm}$ (range $30-91 \mathrm{~cm}, \mathrm{n}=86$ ) and all but one were immature, with a CCL $<83 \mathrm{~cm}$ (J. Mortimer, pers. comm.) Mean CCL of green turtles was $64 \pm \mathrm{SD}_{3} \mathrm{~cm}$ (range $41-106$ $\mathrm{n}=22)$ with $68 \%$ being immature $(\mathrm{CCL}<85 \mathrm{~cm}$, based on the minimum CCL of nesting females in this study).

\section{Migration routes and foraging grounds}

The four nesting green turtle females $\left(\mathrm{V}_{1}, \mathrm{~V}_{2}, \mathrm{~V}_{3}\right.$ and $\left.\mathrm{V}_{4}\right)$ with satellite transmitters started their migration 4-65 days after being tagged (Table 2). They migrated from Vamizi Island to foraging grounds in Tanzania, Kenya and northwest Madagascar (Fig. 6). Three turtles (V1, V2 and $\mathrm{V}_{4}$ ) migrated northwards following similar routes along the African coast for the first $100 \mathrm{~km}$ and passing through Mtwara/Mnazi Bay National Park in southern Tanzania. Turtle V1 then undertook a short phase $50 \mathrm{~km}$ offshore at a greater depth $(1,000-2,000 \mathrm{~m})$ before returning to neritic grounds where she navigated through various marine conservation areas: Rufiji/Mafia/Kilwa National Park and Menai Bay Marine Protected Area in Tanzania, Kisite National Park, Diania National Reserve and Mombasa National Reserve in Kenya (Fig. 6). Her final destination was Watamu National Park in Kenya. Similarly, turtle V4 followed a coastal route, going through the same conservation areas as $\mathrm{V}_{1}$ until reaching foraging ground in Kiunga National Reserve after a 21-day migration. The migration of V2 was shorter and this turtle remained in the neritic zone until reaching feeding ground in the Rufiji/Mafia/Kilwa Marine Protected Area in Tanzania. In contrast, V3 migrated south-east in a near straight line through the North Mozambique Channel, reached the north-western coast of Madagascar near Nosy Makamby and then continued north with a phase of coastal migration until reaching the Mitsio archipelago. Turtles were followed in their foraging ground for a mean of $129.3 \pm$ SD 54.6 days (range 70-193).

\section{Conservation strategies and activities}

Resident fisher communities asked the project to help them in regaining control of the access to their marine resources after it was assessed that overfishing and itinerant fishers represented one of the main threats to their livelihood. Subsequently, two village fisher committees (Conselho Comunitário de Pesca) were created and empowered legally to manage their resources and implement fishing regulations within 3 nautical miles of the coastline, with support and capacity building from the government and the project. Increased awareness of management and ecological issues by these fisher committees led them to create a sanctuary around the north-east of the island, an area that they knew harboured feeding and breeding grounds for turtles as well as critical habitats for fish populations.

The project initiated three micro-projects, in partnership with the Ministry of Environment and the Global Environment Facility, to increase and diversify economic activities on the island. The nature of these activities was chosen by the community and included craft making by women, vegetable farming, and fishing with sustainable fishing methods. These small businesses, together with the creation of employment through tourism and conservation activities, started to generate revenue and to improve the livelihood of the communities using fishing grounds around the island (J. Garnier, pers. obs.).

\section{Discussion}

\section{Nesting activity}

This project is the first long-term intensive monitoring of turtles in Mozambique and East Africa with detailed data 
TABLE 2 Characteristics of post-breeding migrations of four adult green turtles ( $V_{1}, V_{2}, V_{3}, V_{4}$; Fig. 6) fitted with satellite transmitters on Vamizi Island, with date of tagging, date migration began, type of migration route, location of foraging ground, minimum distance travelled, distance travelled to the breeding/foraging ground, duration of migration, and number of days tracked in the foraging ground and overall.

\begin{tabular}{|c|c|c|c|c|}
\hline & $\mathrm{V}_{1}$ & $\mathrm{~V}_{2}$ & $\mathrm{~V}_{3}$ & $\mathrm{~V}_{4}$ \\
\hline Date of tagging & 7 Apr. 2007 & 24 May 2008 & 18 July 2008 & 25 Apr. 2009 \\
\hline Date migration began & 11 Apr. 2007 & 28 July 2008 & 19 Aug. 2008 & 20 May 2009 \\
\hline Migration route & Coastal & Coastal & Oceanic \& coastal & Coastal \\
\hline Foraging ground (country) & $\begin{array}{l}\text { Watamu National } \\
\text { Park (Kenya) }\end{array}$ & $\begin{array}{l}\text { Rufiji/Mafia/Kilwa Marine } \\
\text { Protected Area (Tanzania) }\end{array}$ & $\begin{array}{l}\text { Mitsio archipelago } \\
\text { (Madagascar) }\end{array}$ & $\begin{array}{l}\text { Kiunga National } \\
\text { Reserve (Kenya) }\end{array}$ \\
\hline $\begin{array}{l}\text { Minimum distance } \\
\text { travelled }^{1}(\mathrm{~km})\end{array}$ & 1,098 & 1,017 & 1,181 & 1,223 \\
\hline $\begin{array}{l}\text { Distance to breeding/ } \\
\text { foraging ground }^{2}(\mathrm{~km})\end{array}$ & 1,060 & 400 & 1,350 & 1,270 \\
\hline $\begin{array}{l}\text { Duration of migration } \\
\text { (days) }\end{array}$ & 40 & 9 & 26 & 21 \\
\hline $\begin{array}{l}\text { No. of days tracked in } \\
\text { foraging ground }\end{array}$ & 187 & 152 & 69 & 97 \\
\hline Total no. of days tracked & 231 & 226 & 127 & 143 \\
\hline
\end{tabular}

${ }^{1}$ Straight-line minimum distances travelled were ascertained from reconstructed routes by summing the distance between each best-quality Argos location received in a day for each tagged turtle.

${ }^{2}$ Distance calculated with Satellite Tracking and Analysis Tool (Coyne \& Godley, 2005)

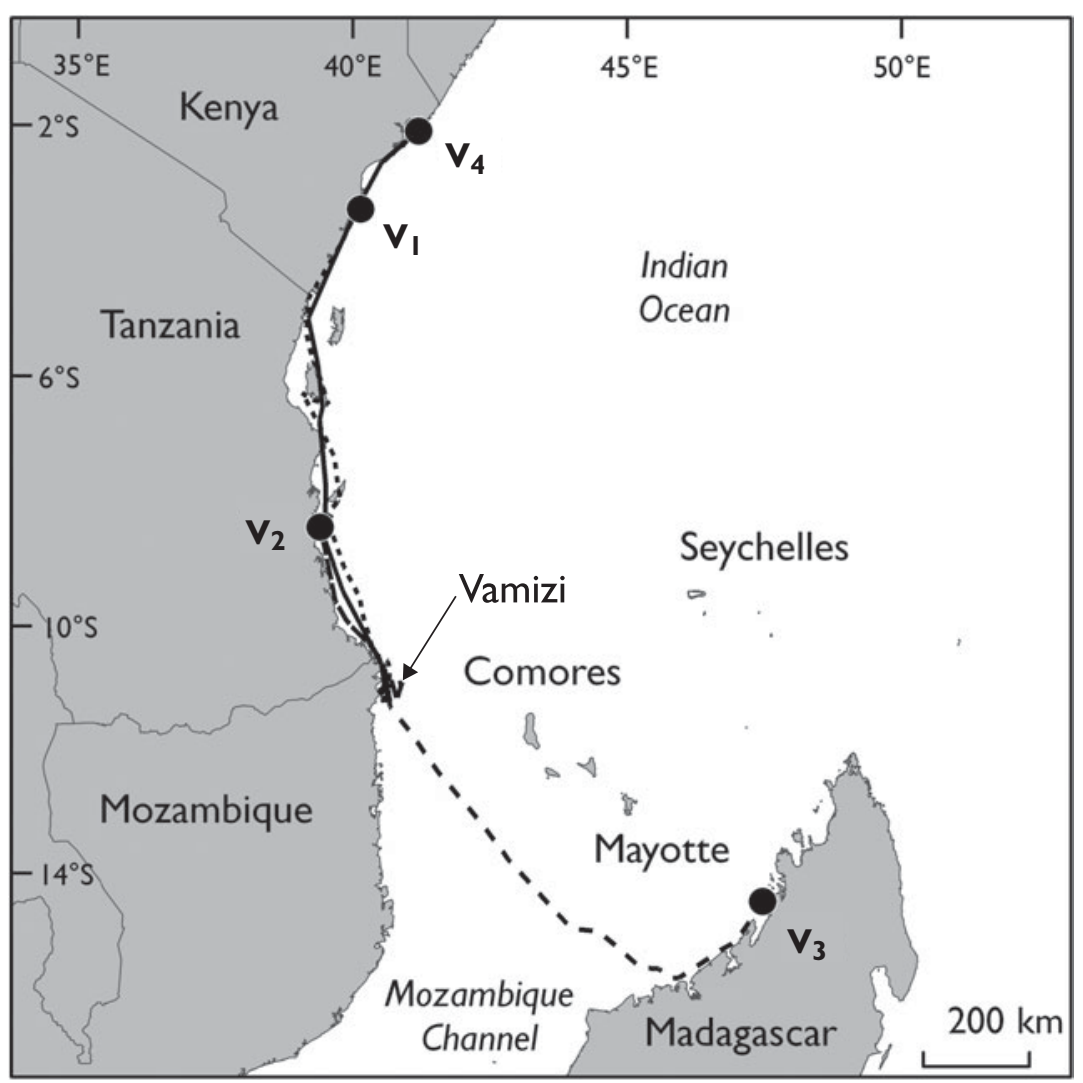

FIG. 6 Migration routes of four tagged adult female green turtles $\left(V_{1}, V_{2}, V_{3}, V_{4}\right)$ between their nesting ground on Vamizi Island and their foraging grounds. Circles are the end points of the tracking data (Table 2). on reproductive output of nesting females and migratory routes of green turtles in this region. The c. 50 female green turtles nesting on Vamizi Island are the most important nesting population of green turtles in Mozambique (Videira et al., 2008), even if the number nesting has been overestimated because of potential underestimation of clutch frequency associated with the partial night coverage of the nesting season and potential tag loss and inaccuracies 
(Broderick et al., 2002). Green turtle nesting activity has only been detected at three other sites in Mozambique (Bazaruto Archipelago National Park, Primeiras and Segundas Archipelago, Querimbas National Park), with a maximum of 20 nests per year (Videira et al., 2008). Regionally, the Vamizi nesting population is much smaller than the large rookeries reported in the South-West Indian Ocean but its proximity to Mayotte and Moheli in the Comoros Archipelago, Aldabra Island in the Seychelles and Grande Glorieuse Island, where green turtle nesting populations are increasing, underlines its contribution to maintaining this species in the region (Le Gall et al., 1986; Seminoff, 2004; Bourjea et al., 2007a). Furthermore, the Vamizi population contributes to the genetic diversity of the green turtle in this region, which harbours populations from both the Atlantic and the Indo-Pacific (Bourjea et al., 2007b).

The generally high percentage nesting success of green turtles on Vamizi Island was close to that reported on Mayotte (Bourjea et al., 2007a). Together with high hatching and emergence successes for non-flooded nests and minimal egg predation, these findings highlight the optimal conditions offered to nesting turtles by this island environment. Our study also showed that nesting occurs all year round, with a peak during the period of highest rainfall, and a marked seasonal cycle of the incubation period, the duration of which was inversely affected by air temperature. Studies of the sex ratio of green turtle hatchlings (reviewed by Godley et al., 2002a) suggest that hatchlings at Vamizi will have a relatively balanced primary sex ratio.

We expect that the Vamizi green turtle population will increase if conservation measures continue to be implemented over several decades, as has been observed at other protected sites (Troëng \& Rankin, 2005; Broderick et al., 2006; Lauret-Stepler et al., 2007). However, nest loss through inundation, which affected the nesting beaches on the island in 2007, is of concern. A similar occurrence was observed in southern Mozambique on the Bazaruto archipelago where all nests were lost in 2007 (Videira et al., 2008), which might be indicative of a regional or global event. The loss of nesting habitat is one of the main impacts of climate change on turtle populations, especially on lowlying islands (Hawkes et al., 2009), and this needs to be closely monitored.

Although hawksbill turtle nests were observed in low numbers on Vamizi their density is the highest known for this species in Mozambique (Videira et al., 2008). The low numbers reflect the decline of this species in the Western Indian Ocean (Mortimer \& Donnelly, 2008). The close proximity of Vamizi to the Tanzanian border makes the hawksbill population of this site particularly vulnerable as the country has been a focal point for regional trade in turtle shells (Mortimer \& Donnelly, 2008) and itinerant fishers from Tanzania have increasingly entered the northern Querimbas Islands (Garnier, 2003).

\section{Migration routes and foraging grounds}

This is the first published record of satellite tracking of green turtles along the East African coast and the first description of green turtle migration routes in this region. Other satellite telemetry studies with turtles in the Western Indian Ocean have either involved the manipulation of study animals to investigate their navigational capabilities or loggerhead and leatherback turtles (reviewed in Luschi et al., 2006; Godley et al., 2008). Post-nesting movements of green turtles tagged on Vamizi involved both oceanic and coastal routes, with a combination of both in one turtle $\left(\mathrm{V}_{3}\right)$. Although our sample size was small, the data suggests that the location of the Querimbas Islands relative to prevailing oceanographic currents may play a role in the diversity of foraging grounds used by green turtle populations nesting there.

Another important finding of our study is the use of marine protected areas during post-nesting migration and foraging. Turtles $\mathrm{V}_{1}, \mathrm{~V}_{2}$ and $\mathrm{V}_{4}$, which migrated along the East African coast, travelled through up to seven marine conservation areas and they all had a foraging ground located in a protected area. Green turtles have been found to exhibit high levels of fidelity to migratory routes and foraging areas, thus strengthening the argument for controlling threats in these areas (Broderick et al., 2007).

With at least four nations as stakeholders for this Western Indian Ocean population our satellite-tracking study also highlights the importance of developing regional conservation strategies for green turtles, and the importance of consolidating existing marine protected area networks. Conservation of marine turtles has generally focused on nesting grounds but transboundary conservation initiatives are required to ensure the protection of migratory corridors.

\section{Other conservation strategies and activities}

Community-based monitoring of turtle nesting activity is important for providing data for development of conservation strategies and also for actively involving local communities. This strategy proved to be successful as slaughter of nesting turtles on the beach, considered to be high before the project started, was considerably reduced afterwards. This may be explained by the fact that the local monitors not only acquired gainful employment but may have disseminated their knowledge of turtles and associated conservation ethics within their community (cf. Marcovaldi \& Marcovaldi, 1999).

Awareness campaigns and incentive programmes conducted by the project with resource users in local fishing communities may have reduced turtle mortality through bycatch because local fishers became aware of the ecological and economic value of turtles, as well as their legal status. Such incentive programmes have also been used successfully in Kenya and Tanzania (Okemwa et al., 2004; Muir, 2005). 
However, it is essential to monitor the outputs closely to ensure that fishers do not transform their activities to that based solely on turtle catching. Through the identification of turtles caught by fishers we were able to assess the importance of the project area for immature turtles, especially hawksbill turtles. The fact that coastal habitats around the northern Querimbas Islands support populations of both nesting and maturing hawksbill turtles emphasizes the area's regional importance and would justify the expansion of similar community-based conservation initiatives to other fishing villages in the area.

The development of alternative economic activities and income-generating sustainable fisheries by the project contributed to the decision by communities to self-regulate fishing pressure and to create a marine sanctuary. Developing alternative economic activities is a well-recognized conservation strategy that has been used successfully in other turtle conservation programmes (Moreira, 2001) but its viability needs to be closely assessed beforehand.

The community-based management systems that were formed on Vamizi Island will contribute to the management of local threats such as coastal gill net fisheries, which pose a serious threat to turtles around Vamizi Island (Garnier, 2003), as in the rest of the Western Indian Ocean (Kiszka \& Muir, 2007). However, such strategies need to be complemented by broader government conservation measures to protect turtle populations against other major threats that, for Vamizi, include incursion by industrial long-liners and possible seismic exploration activities.

This project has identified a new site of regional importance for green and hawksbill turtles in the Western Indian Ocean and made significant progress towards protecting this site. Although the development of community-based management systems will facilitate the long-term sustainability of this programme the protection of coastal resources and turtles will only be ensured if the social and economic interests of communities, as well as of government, are considered. We have begun to address the issues of alternative and sustainable livelihoods with the local communities but there is a need to work with the government and international companies to ensure that the attraction of short-term benefits does not outweigh the longer-term requirements of sustainable conservation.

\section{Acknowledgements}

We are grateful to the European Association of Zoo and Aquaria, the Global Environment Facility, Tusk Trust, the Maluane project and private donors for their financial support to this long-term conservation effort, and for collaboration with MICOA (Ministry of Environment), IDPPE (Institute of Small-scale Fisheries), the Fisheries Department (Ministry of Agriculture), and AMA (Association for the Environment). This project would never have achieved its results without the hard work of the conservation team and the turtle monitors, who are working to reconcile the needs of both turtles and people.

\section{References}

Allen, Z.C., Shah, N.J., Grant, A., Derand, G.D. \& Bell, D. (2010) Hawksbill turtle monitoring in Cousin Island Special Reserve, Seychelles: an eight-fold increase in annual nesting numbers. Endangered Species Research, 11, 195-200.

Bolten, A.B. (1999) Techniques for measuring sea turtles. In Research and Management Techniques for the Conservation of Sea Turtles (eds K.L. Eckert, K.A. Bjorndal, F.A. Abreu-Grobois \& M. Donnelly), pp. 110-114. IUCN/Species Survival Commission Marine Turtle Specialist Group, Washington, USA.

Bourjea, J., Ciccione, S. \& Rantsimbazafy, R. (2006) Marine turtle survey in Nosy Iranja Kely, north-western Madagascar. Western Indian Ocean Journal of Marine Science, 5, 209-212.

Bourjea, J., Frappier, J., Quillard, M., Ciccione, S., Ross, D., Hughes, G. \& Grizel, H. (2007a) Mayotte Island: another important green turtle nesting site in the southwest Indian Ocean. Endangered Species Research, 3, 273-282.

Bourjea, J., Lapègue, S., Gagnevin, L., Broderick, D., Mortimer, J.A., Ciccione, S. et al. (2007b) Phylogeography of the green turtle, Chelonia mydas in the Southwest Indian Ocean. Molecular Ecology, 16, 175-186.

Broderick, A.C., Coyne, M.S., Fuller, W.J., Glen, F. \& Godley, B.J. (2007) Fidelity and over-wintering of sea turtles. Proceedings of the Royal Society B: Biological Sciences, 274, $1533-1538$.

Broderick, A.C., Frauenstein, R., Glen, F., Hays, G.C., Jackson, A.L., Pelembe, T. et al. (2006) Are green turtles globally endangered? Global Ecology and Biogeography, 15, 21-26.

Broderick, A.C., Glen, F., Godley, B.J. \& Hays, G.C. (2002) Estimating the number of green and loggerhead turtles nesting annually in the Mediterranean. Oryx, 36, 227-236.

Costa, A., Motta, H., Pereira, M.A., Videira, E.J., Louro, C.M. \& Jo ̃̃ O, J. (2007) Marine Turtles in Mozambique: towards an effective conservation and management program. Marine Turtle Newsletter, $117,1-3$.

Coyne, M.S. \& Godley, B.J. (2005) Satellite Tracking and Analysis Tool (STAT): an integrated system for archiving, analyzing and mapping animal tracking data. Marine Ecology Progress Series, 301, $1-7$.

Frazier, J. (1975) Marine turtles of the western Indian Ocean. Oryx, 13, 164-175.

Garnier, J. (2003) Cabo Delgado Biodiversity and Tourism Project. Management Plan (2003-2006). Cabo Delgado Biodiversity and Tourism Project, Bairro Natite, Pemba, Mozambique.

Garnier, J., Silva, I., Davidson, J., Hill, N., Muaves, L., Mucaves, S. et al. (2008) Co-management of the reef at Vamizi Island, northern Mozambique. In Ten Years after Bleaching-Facing the Consequences of Climate Change in the Indian Ocean (eds D.O. Obura, J. Tamelander \& O. Linden), pp. 121-128. Cordio Status Report 2008, Coastal Oceans Research and Development in the Indian Ocean/Sida-SAREC, Mombasa, Kenya.

Godley, B.J., Blumenthal, J.M., Broderick, A.C., Coyne, M.S., Godfrey, M.H., Hawkes, L.A. \& Witt, M.J. (2008) Satellite tracking of sea turtles: where have we been and where do we go next? Endangered Species Research, 4, 3-22.

Godley, B.J., Broderick, A.C., Glen, F. \& Hays, G.C. (2002a) Temperature dependent sex determination of Ascension Island green turtles. Marine Ecology Progress Series, 226, 115-124. 
Godley, B.J., Broderick, A.C. \& Hays, G.C. (2001) Nesting of green turtles (Chelonia mydas) at Ascension Island, South Atlantic. Biological Conservation, 97, 151-158.

Godley, B.J., Richardson, S., Broderick, A.C., Coyne, M.S., GLEN, F. \& HAYS, G.C. (2002b) Long-term satellite telemetry of the movements and habitat utilization by green turtles in the Mediterranean. Ecography, 25, 352-362.

Gove, D. \& MAgane, S. (1996) The status of sea turtle conservation in Mozambique. In Status of Sea Turtle Conservation in the Western Indian Ocean (eds S.L. Humpfrey \& R.V. Salm), pp 89-94. Regional Seas Reports and Studies, No 165. IUCN/UN Environment Programme, Nairobi, Kenya.

Hays, G.C., Akesson, S.A., Godley, B.J., Luschi, P. \& Santadrian, P. (2001) The implications of local accuracy for the interpretation of satellite tracking data. Animal Behaviour, 61, 1035-1040.

Hays, G.C., Broderick, A.C., Godley, B.J., Lovell, P., Martin, C., MCConnell, B.J. \& Richardson, S. (2002) Biphasal long-distance migration in green turtles. Animal Behaviour, 64, 895-898.

Hawkes, L.A., Brodrick, A.C., Godfrey, M.H. \& Godley, B.J. (2009) Climate change and marine turtles. Endangered Species Research, 7, 137-154.

Hill, N.A., Davidson, J., Silva, I., Mucave, S., Muaves, L., Guissamulo, A. et al. (2009) Coral and reef fish in the northern Quirimbas Archipelago, Mozambique-a first assessment. Western Indian Ocean Journal of Marine Science, 8, 113-125.

Hughes, G.R. (1971) Preliminary report on the sea turtles and dugongs of Mozambique. Veterinaria Moçambicana, 4, 43-84.

Hughes, G.R. (1996) Nesting of the leatherback turtle (Dermochelys coriacea) in Tongaland, Kwa-Zulu-Natal, South Africa, 1963-1995. Chelonian Conservation Biology, 2, 153-158.

IUCN (2011) IUCN Red List of Threatened Species v. 2011.1. http://www. iucnredlist.org [accessed 16 August 2011].

Johnson, S.A. \& Ehrhart, L.M. (1996) Reproductive ecology of the Florida green turtle: clutch frequency. Journal of Herpetology, 30, 407-410.

KiszKa, J. \& Muir, C. (eds) (2007) Incidental Catch of Non-Targeted Marine Species in the Western Indian Ocean. Problems and Mitigation Measures. Workshop Proceedings, 13-15th November 2006, Mayotte, France.

Lauret-Stepler, M., Bourjea, J., Roos, D., Pelletier, D., Ryan, P., Ciccione, S. \& Grizel, H. (2007) Reproductive seasonality and trend of Chelonia mydas in the SW Indian Ocean: a 20 yr study based on track counts. Endangered Species Research, 3, $217-227$.

Le Gall, J.Y., Bosc, P., Chateau, D. \& Taquet, M. (1986) Estimation du nombre de tortues vertes femelles adultes Chelonia mydas par saison de ponte a Tromelin et Europa (Océan Indien) (1973-1985). Océanographie Tropicale, 21, 3-22.

Louro, C.M., Pereira, M.A. \& Costa, A.C. (eds) (2006) Report on the Conservation Status of Marine Turtles in Mozambique. Ministerio para a Coordenação da Ação Ambiental, Maputo, Mozambique.

Luschi, P., Hays, G.C., Del Seppia, C., Marsch, R. \& Papi, F. (1998) The navigational feats of green sea turtles migrating from Ascension Island investigated by satellite telemetry. Proceedings of the Royal Society B, 265, 2279-2284.

Luschi, P., Lutjeharm, J.R.E., Lambardi, R., Mencacci, R., Hughes, G.R. \& Hays, G.C. (2006) A review of migratory behaviour of sea turtles off southeastern Africa. South African Journal of Science, 102, 51-58.

Lutjeharms, J.R.E., Wedepoh, P.M. \& Meeuwis, J.M. (2000) On the surface drift at the East Madagascar and the Mozambique Currents. South African Journal of Science, 96, 141-147.
Marcovaldi, M.A.A. \& Marcovaldi, G.G. (1999) Marine turtles of Brazil: the history and structure of Projeto TAMAR-IBAMA.

Biological Conservation, 91, 35-41.

Miller, J.D. (1999) Determining clutch size and hatching success. In Research and Management Techniques for the Conservation of Sea Turtles (eds K.L. Eckert, K.A. Bjorndal, F.A. Abreu-Grobois \& M. Donnelly), pp. 124-129. IUCN/Species Survival Commission Marine Turtle Specialist Group, Washington, USA.

Moreira Lima, E.H.S. (2001) Helping the people help the turtles: the mark of Projeto Tamar-Ibama in Almofala, Brazil. Marine Turtle Newsletter, 91, 7-9.

Mortimer, J.A. (1985) Recovery of green turtles on Aldabra. Oryx, 19, 146-150.

Mortimer, J.A. (2006) Simple, yet effective: protection at the nesting beach. State of the World's Sea Turtles Report, (ed. R. Mast), p. 8. SWOT Report, Vol. I. Arlington, USA.

Mortimer, J.A. \& Donnelly, M. (2008) Eretmochelys imbricata. In IUCN Red List of Threatened Species v. 2011.1. http://www.iucnredlist. org [accessed 16 August 2011].

Muir, C. (2005) The Status of Marine Turtles in the Republic of Tanzania, East Africa. Sea Sense, Dar es Salaam, Tanzania.

Oкемwa, G.M., Nzuki, S. \& Mueni, E.M. (2004) The status and conservation of sea turtles in Kenya. Marine Turtle Newsletter, 105, 1-6.

Pritchard, P.C.H. \& Mortimer, J.A. (1999) Taxonomy, external morphology and species identification. In Research and Management Techniques for the Conservation of Sea Turtles (eds K.L. Eckert, K.A. Bjorndal, F.A. Abreu-Grobois \& M. Donnelly), pp. 21-40. IUCN/Species Survival Commission Marine Turtle Specialist Group, Washington, USA.

Schouten, M.W., Ruijter, W.P.M., Leeuwen, P.J.V. \& RidderinkHOF, H. (2003) Eddies and variability in the Mozambique Channel. Deep-Sea Research, II, 1987-2003.

Schroeder, B. \& Murphy, S. (1999) Population surveys (ground and aerial) on nesting beaches. In Research and Management Techniques for the Conservation of Sea Turtles (eds K.L. Eckert, K.A. Bjorndal, F.A. Abreu-Grobois \& M. Donnelly), pp. 45-55. IUCN/Species Survival Commission Marine Turtle Specialist Group, Washington, USA.

SEminoff, J.A. (2004) Chelonia mydas. In IUCN Red List of Threatened Species v. 2011.1. http://www.iucnredlist.org [accessed 16 August 2011].

TroËNG, S. \& RANKIN, E. (2005) Long-term conservation efforts contribute to positive green turtle Chelonia mydas nesting trend at Tortuguero, Coasta Rica. Biological Conservation, 121, $111-116$.

Videira, E.J., Pereira, M.A., Louro, C.M. \& Narane, D.A. (2008) Monitoria, marcação e conservação de tortarugas marinhas em moçambique: dados históricos e relatório anual 2007/08. Grupo de Trabalho Tartarugas Marinhas de Moçambique, Maputo, Moçambique.

\section{Biographical sketches}

JULie GARNIER is a wildlife veterinarian specializing in biodiversity conservation, with a focus on community development and livelihoods. She created and ran the Maluane conservation programme in Mozambique for 10 years. NICK HILl studies socio-economic issues in marine conservation. He and ISA B EL SILVA were the resident marine biologists on Vamizi. A L M E ID A GU ISS A M U LO is a marine biologist with a focus on the conservation of coastal and marine mammals. MATTHEW W Iт T is a spatial ecologist who specializes in marine vertebrates and fisheries. BRENDAN GODLEY is a conservation biologist focusing on marine issues. 